\title{
Rhodium Tin Composite Oxides Co-catalyst for High Efficient Photocatalytic Hydrogen Evolution
}

\author{
Zhen $\mathrm{Li}^{a, b}$, Chao Kong ${ }^{a, b}$, Gongxuan Lu ${ }^{a^{*}}$ \\ ${ }^{\text {a }}$ State Key Laboratory for Oxo Synthesis and Selective Oxidation, Lanzhou Institute of \\ Chemical Physics, Chinese Academy of Science, Lanzhou 730000, China \\ ${ }^{\mathrm{b}}$ University of Chinese Academy of Science, Beijing 10080, China. \\ *Corresponding author: E-mail: gxlu@lzb.ac.cn. \\ Tel.: +86-931-4968 178 .
}

\begin{abstract}
In this work, we studied the modification of surface active site of $\mathrm{Rh}$ in $\mathrm{RhSn}_{\mathrm{x}} \mathrm{O}_{\mathrm{y}}$ composite oxide co-catalyst by the addition of $\mathrm{Sn}$ for high efficient photocatalytic hydrogen evolution under visible light irradiation. The significant activity promotion was accomplished by the adjustment of Rh sites via Sn addition. After sensitized by Eosin $\mathrm{Y}(\mathrm{EY})$ dye, the $\mathrm{RhSn}_{\mathrm{x}} \mathrm{O}_{\mathrm{y}}$ co-catalyst exhibited the apparent quantum efficiency (AQE) of $21.0 \%$ at $430 \mathrm{~nm}$ for hydrogen generation. Under optimized conditions, the highest hydrogen evolution rate of $1280.3 \mu \mathrm{mol} \cdot \mathrm{h}^{-1}$ (corresponding TON 64) over $\mathrm{RhSn}_{\mathrm{x}} \mathrm{O}_{\mathrm{y}}$ co-catalyst was achieved, which was 8.3 times higher than that of $\mathrm{Rh}$ co-catalyst. Based on the XRD and XPS characterizations, Rh atom arrangement on the surface of $\mathrm{RhSn}_{\mathrm{x}} \mathrm{O}_{\mathrm{y}}$ co-catalyst was confirmed. By adjusting $\mathrm{Rh}$ sites, it showed significantly different interaction between $\mathrm{Rh}$ atoms and $\mathrm{Sn}$ atoms, which led to more efficient excited charge separation and transfer from $\mathrm{Rh}$ atoms to $\mathrm{Sn}$ atoms with the amount of Sn increased, resulting in more effective photo-induced hydrogen generation.
\end{abstract} Keywords: Photocatalysis, Visible light, Hydrogen evolution, Co-catalyst, $\mathrm{RhSn}_{\mathrm{x}} \mathrm{O}_{\mathrm{y}}$, Eosin Y Sensitization. 


\section{Introduction}

Hydrogen is one of stable, clean and renewable energy carriers, which is considered as an ideal alternative energy carrier to solve the problems of fossil energy consumption and related environmental pollution problems. Many efforts have been devoted to find the methods for efficient hydrogen generation, such as alkanes reforming [1-5], biological fermentation [6] and photocatalysis [7]. Among them, using free and sustainable solar energy to produce hydrogen is a promising route because there is no net carbon dioxide emission in this process. In a typical photocatalytic hydrogen evolution system, an electron donor, a proton reducing co-catalyst and a photosensitizer are usually necessary [8-10]. Among them, the co-catalyst plays a key role in hydrogen evolution reaction since it not only provides a proton reduction and hydrogen formation site, but also induces the excited electron to efficiently separate with hole to get a prolonged lifetime. Recently, several excellent co-catalysts have been reported, for example, the Pt nanoparticles immobilized on functionalized graphene, which can effectively enhance the separation of electrons and holes, and promote activity of catalyst under visible irradiation [11-12].

Nobel metals are frequently used as co-catalysts because of their highly activity and low overpotential for hydrogen evolution [13]. It is only recently known that the surface arrangement of those $\mathrm{Pt}$ or $\mathrm{Rh}$ atoms determines the separation, transfer and reaction of excited charges [11-12]. And those phenomena have been also observed in other non-noble metal co-catalysts, such as transition metal, transition metal oxides and transition metal sulfides [14]. Our previous works indicated that the surface arrangement of co-catalyst could be adjusted by Sn addition [15-16]. By modifying the surface active site of hydrogen evolution by $\mathrm{Sn}$ in Pt-Sn alloy, hydrogen atom migration from $\mathrm{Pt}$ to $\mathrm{Sn}$ was achieved, as a result, the enhancement of hydrogen molecules desorption over this catalyst was accomplished.

In our present work, the modification of surface active site of Rh and its effect on photocatalytic hydrogen evolution were studied in $\mathrm{RhSn}_{\mathrm{x}} \mathrm{O}_{\mathrm{y}}$ co-catalyst. After sensitized by Eosin Y (EY), this photocatalyst exhibited highly activity of hydrogen evolution and 
excellent stability under visible light irradiation $(\lambda \geq 420 \mathrm{~nm})$. The results of XRD and XPS characterizations showed that the Rh sites on the surface of $\mathrm{RhSn}_{\mathrm{x}} \mathrm{O}_{\mathrm{y}}$ co-catalyst could be adjusted by adding different amount of Sn. More efficient charge separation and transfer from $\mathrm{Rh}$ atom to $\mathrm{Sn}$ atom leads to more effective photo-induced hydrogen generation over optimized ratios of $\mathrm{Rh}$ and $\mathrm{Sn}$ in $\mathrm{RhSn}_{\mathrm{x}} \mathrm{O}_{\mathrm{y}}$ co-catalysts.

\section{Experimental section}

\subsection{Photocatalytic Hydrogen Evolution Activity and AQY Measurements.}

Preparation of co-catalysts was performed in a sealed Pyrex flask $(170 \mathrm{~mL})$ with a flat window (an efficient irradiation area of $10.2 \mathrm{~cm}^{2}$ ) and a silicone rubber septum for sampling at room temperature. A series of other co-catalysts were prepared by in situ reaction under visible light irradiation $(\lambda \geq 420 \mathrm{~nm})$ using rhodium (III) chloride $\left(\mathrm{RhCl}_{3}\right)$ and tin (IV) chloride $\left(\mathrm{SnCl}_{4}\right)$ aqueous solution as precursors. Typically, $2 \mathrm{ml}$ of $\mathrm{RhCl}_{3}$ aqueous solution $\left(1.0 \times 10^{-2} \mathrm{~mol} / \mathrm{L}\right)$ was added dropwise into $100 \mathrm{ml}$ of triethanolamine (TEOA) $-\mathrm{H}_{2} \mathrm{O}$ solution (10\%, v/v) by magnetic stirring. Then, $1.32 \mathrm{ml} \mathrm{SnCl}_{4}$ aqueous solution $(0.3 \mathrm{~mol} / \mathrm{L})$ was added in the same way. After stirring ten minutes, $70 \mathrm{mg}$ of Eosin Y (EY) was added and treated another two minutes to make the reactants fully dissolve by ultrasound. The $\mathrm{pH}$ values of the reaction solution were adjusted by addition of hydrochloric acid or sodium hydroxide. The reference $\mathrm{Rh}_{2} \mathrm{O}_{3}$ co-catalyst was also prepared by hydrothermal method. Calculated amount of $\mathrm{RhCl}_{3}$ was dissolved in the mixture water and potassium citrate, then was heated at $95^{\circ} \mathrm{C}$. The Rh content was about $0.4 \mathrm{mg} / \mathrm{ml}$. Prior to irradiation, the reactant mixture was degassed by bubbling Ar gas for $30 \mathrm{~min}$. The light source was a $300-\mathrm{W}$ Xe lamp, equipped with either a $420 \mathrm{~nm}$ cut-off filter or various band-pass filters for AQEs tests. Photon flux of the incident light was determined using a Ray virtual radiation actinometer (FU 100, silicon ray detector, light spectrum, 400 700 nm; sensitivity, $10 \sim 50 \mu \mathrm{V} \mu \mathrm{mol}^{-1} \mathrm{~m}^{-2} \mathrm{~S}^{-1}$ ). A magnetic stirrer was used to keep the catalyst in suspension. The amount of hydrogen evolution was detected by gas chromatography (Aglient 6820, TCD, column: $13 \mathrm{X}, \mathrm{Ar}$ as carrier gas). The following equation was used to calculate the AQEs. 
AQEs $=2 \mathrm{X}$ (the number of evolved hydrogen molecules) $/$ (the number of incident photons) $\times 100 \%$

\subsection{Characterizations.}

TEM (Transmission electron microscopy), HRTEM (high-resolution Transmission electron microscopy), HAADF-STEM (high angle annular dark field scanning transmission electron microscopy) and elemental mapping images were performed with a Tecnai-G2-F30 field emission transmission electron microscope operating at an accelerating voltage of $300 \mathrm{kV}$. The XRD (X-ray diffraction) patterns of the samples were recorded on a Rigaku B/Max-RB diffractometer with a nickel filtrated $\mathrm{Cu} \mathrm{K} \alpha$ radiation. The accelerating voltage and current were $40 \mathrm{kV}$ and $30 \mathrm{~mA}$, respectively. XPS (X-ray photoelectron spectroscopy) analysis was taken using a VG Scientific ESCALAB210-XPS photoelectron spectrometer with an $\mathrm{Mg} \mathrm{K \alpha}$ X-ray resource.

\section{Results and discussions}

The time course of hydrogen evolution catalyzed by the dye-sensitized co-catalysts with different atomic ratio of $\mathrm{Sn}$ and $\mathrm{Rh}(0: 1,1: 1,5: 1,10: 1,15: 1,20: 1$ and 1:0) at pH 7 under visible light irradiation $(\lambda \geq 420 \mathrm{~nm})$ were shown in Fig. 1. A negligible amount of hydrogen evolution $(2.5 \mu \mathrm{mol}$ in $60 \mathrm{~min})$ was produced when $\mathrm{Sn}$ was used only. This result indicated that $\mathrm{Sn}$ specie was inactive for hydrogen evolution. Similarly, a little amount of hydrogen $(155.1 \mu \mathrm{mol}$ in $60 \mathrm{~min})$ was produced over Rh co-catalyst, indicating that the Rh specie had low activity for hydrogen evolution. But the hydrogen generation activity of $\mathrm{Rh}$ increased significantly with the addition of $\mathrm{Sn}$, and the activity reached the highest point $(1280.3 \mu \mathrm{mol}$ in $60 \mathrm{~min}$, 8.3 times higher that hydrogen evolution amount over $\mathrm{Rh}$ ) when the atomic ratio of $\mathrm{Sn}$ and $\mathrm{Rh}$ was 10: 1. But further increasing the atomic ratio of $\mathrm{Sn}$ and $\mathrm{Rh}$ exhibited the weak effect on the hydrogen generation activity over $\mathrm{RhSn}_{\mathrm{x}} \mathrm{O}_{\mathrm{y}}$ co-catalyst. $\mathrm{Rh}_{2} \mathrm{O}_{3}$ co-catalyst showed $321.6 \mu \mathrm{mol} / \mathrm{h}$ hydrogen but is was much lower than $\mathrm{RhSn}_{\mathrm{x}} \mathrm{O}_{\mathrm{y}}$ co-catalyst. 
Fig. 2 shows the time course of hydrogen evolution catalyzed by the dye-sensitized $\mathrm{RhSn}_{\mathrm{x}} \mathrm{O}_{\mathrm{y}}$ photocatalytic system at $\mathrm{pH} 7$ under visible light irradiation $(\lambda \geq 420 \mathrm{~nm})$. It was clear that the amount of hydrogen evolution increased quickly with the increase of $\mathrm{RhSn}_{\mathrm{x}} \mathrm{O}_{\mathrm{y}}$ amount, and the hydrogen evolution rate reached the highest point (1280.3 $\mu \mathrm{mol} \cdot \mathrm{h}^{-1}$ ) when the added amount of $\mathrm{RhSn}_{\mathrm{x}} \mathrm{O}_{\mathrm{y}}$ co-catalyst was $20 \mu \mathrm{mol}$. The optimized the atomic ratio of $\mathrm{Sn}$ and $\mathrm{Rh}$ was 10: 1 . The optimal $\mathrm{RhSn}_{\mathrm{x}} \mathrm{O}_{\mathrm{y}}$ co-catalyst dosage was $20 \mu \mathrm{mol}$ in reaction system.

The effect of $\mathrm{pH}$ on activity of $\mathrm{RhSn}_{\mathrm{x}} \mathrm{O}_{\mathrm{y}}$ sensitized by EY was shown in Fig. 3 (A), the activity of $\mathrm{RhSn}_{\mathrm{x}} \mathrm{O}_{\mathrm{y}}$ was highly dependent on the $\mathrm{pH}$ of reaction system. The optimum $\mathrm{pH}$ was around 7, corresponding the rate of hydrogen evolution was 1280.3 $\mu \mathrm{mol} \cdot \mathrm{h}^{-1}$. No hydrogen evolution was observed at $\mathrm{pH} 2$ and 4 , which was likely due to the protonation of TEOA and EY in acidic solution. That protonation process would impact the electron-donating properties of TEOA [17] and the absorption performance of EY in the visible light region. In alkaline solution, the hydrogen evolution activity of $\mathrm{RhSn}_{\mathrm{x}} \mathrm{O}_{\mathrm{y}}$ dropped rapidly with the increase of $\mathrm{pH}$, only $85.9 \mu \mathrm{mol}$ of hydrogen was produced in 60 min at $\mathrm{pH} 12$. It might result from the decreasing of $\mathrm{H}^{+}$concentration. Apparent quantum efficiencies (AQEs) of EY-RhSn ${ }_{x} \mathrm{O}_{\mathrm{y}}$ system were measured from 430 to $550 \mathrm{~nm}$, and the results were shown in Fig. 3 (B). Under optimized conditions, the highest AQE reached $21.0 \%$ at $430 \mathrm{~nm}$, due to the high photon energy. The AQE was about $12 \%$ at $518 \mathrm{~nm}$ which corresponded to the highest absorption peak of EY [9-10].

Since the structure of $\mathrm{RhSn}_{\mathrm{x}} \mathrm{O}_{\mathrm{y}}$ co-catalysts might be also affected by the atomic ratios of $\mathrm{Sn}$ and $\mathrm{Rh}$, which could determine the affinity of hydrogen atom on the co-catalyst surface, $\mathrm{RhSn}_{\mathrm{x}} \mathrm{O}_{\mathrm{y}}$ co-catalyst with the different atomic ratios of $\mathrm{Sn}$ and $\mathrm{Rh}$ were investigated by XRD. As shown in Fig. 4, the typical diffraction peaks of $\mathrm{SnO}_{2}$ centered at $26.6,33.7,51.6$ and $65.7^{\circ}$ were observed in $\mathrm{RhSn}_{\mathrm{x}} \mathrm{O}_{\mathrm{y}}$ co-catalysts. Those peaks could be attributed to (110), (101), (211) and (301) facets of tetragonal $\mathrm{SnO}_{2}$ (JCPDS\#88-0287), respectively. However, the typical peaks for (111) facet shifted from $26.58^{\circ}$ (low $\mathrm{Rh}$ loading sample, $\mathrm{Sn}: \mathrm{Rh}=1: 1$ ) to $26.25^{\circ}$ (high $\mathrm{Rh}$ sample, $\mathrm{Sn}: \mathrm{Rh}=15: 1$ ), which implied the structure of $\mathrm{SnO}_{2}$ could be adjusted by $\mathrm{Rh}$ atoms. In addition, no other typical diffraction peaks were observed in $\mathrm{RhSn}_{\mathrm{x}} \mathrm{O}_{\mathrm{y}}$ samples with the different 5 
atomic ratios of $\mathrm{Sn}$ and $\mathrm{Rh}$, which implied that $\mathrm{Rh}$ was highly dispersed in all $\mathrm{RhSn}_{\mathrm{x}} \mathrm{O}_{\mathrm{y}}$ co-catalysts samples. The calculated particle size of $\mathrm{RhSn}_{\mathrm{x}} \mathrm{O}_{\mathrm{y}}$ co-catalysts by the Scherrer formula was $5.8 \mathrm{~nm}$.

Transmission electron microscopy (TEM) image of the typical $\mathrm{RhSn}_{\mathrm{x}} \mathrm{O}_{\mathrm{y}}$ was given in Fig. 5. As shown in Fig. 5 (A), $\mathrm{RhSn}_{\mathrm{x}} \mathrm{O}_{\mathrm{y}}$ nanoparticles are distributed uniformly and their size are all less than $10 \mathrm{~nm}$. According to the distribution of particle size shown in Fig. 5(D), the average size was $5.3 \pm 0.7 \mathrm{~nm}$, with sizes ranging from 4.9 to $6.0 \mathrm{~nm}$. This result was in good agreement with the result of XRD $(5.8 \mathrm{~nm})$. The high-resolution TEM (HRTEM) image $(\mathrm{Sn}: \mathrm{Rh}=10: 1)$ (Fig. $5 \mathrm{~B})$ showed that the co-catalysts were well crystalized. The lattice spacing of $0.34 \mathrm{~nm}$ could be assigned to (110) facet of $\mathrm{SnO}_{2}$ (JCPDS\#77-0452) and the lattice spacing of $0.27 \mathrm{~nm}$ could be attributed to (121) facet of $\mathrm{Rh}_{2} \mathrm{O}_{3}$ (JCPDS\#76-0148). Simultaneously, the element composition of co-catalyst was also detected and the results were presented in Fig. 5(C), which indicated that the $\mathrm{Rh}, \mathrm{Sn}$ and $\mathrm{O}$ were highly and homogeneously dispersed in $\mathrm{RhSn}_{\mathrm{x}} \mathrm{O}_{\mathrm{y}}$ co-catalyst.

The surface chemical state of Sn and Rh might be affected by the value of Sn: Rh, which in turn determined the affinity of hydrogen atom on the co-catalyst surface. The XPS characterization results of $\mathrm{RhSn}_{\mathrm{x}} \mathrm{O}_{\mathrm{y}}$ co-catalysts were shown in Fig. 6 (A). The binding energy of $\mathrm{Sn} 3 \mathrm{~d}_{5 / 2}$ shifted from $486.7 \mathrm{eV}$ (high Rh loading sample, $\mathrm{Sn}: \mathrm{Rh}=1: 1$ ) to $487.3 \mathrm{eV}$ (low $\mathrm{Rh}$ sample, $\mathrm{Sn}: \mathrm{Rh}=15: 1$ ). These results indicated that the chemical state of Sn could be partially adjusted by the addition of Rh because the arrangement of Sn atoms on the surface of $\mathrm{SnO}_{2}$ could be changed by $\mathrm{Rh}$ atoms. The XPS results further indicated that the chemical environment of Sn changed to more negative value when the amount of $\mathrm{Rh}$ increased. It implied that the charge transfer tendency from $\mathrm{Rh}$ atom to $\mathrm{Sn}$ atom in $\mathrm{RhSn}_{\mathrm{x}} \mathrm{O}_{\mathrm{y}}$ co-catalyst, and those charge transfer tendency could be controlled by $\mathrm{Rh}$ atom arrangement on the co-catalyst surface. This interaction was also strongly supported by Rh $3 d_{5 / 2}$ XPS results. As shown in Fig. 6 (B), the binding energy of $R h$ $3 \mathrm{~d}_{5 / 2}$ shifted from $309.2 \mathrm{eV}$ (high Rh loading sample, $\mathrm{Sn}: \mathrm{Rh}=1: 1$ ) to $309.9 \mathrm{eV}$ (low $\mathrm{Rh}$ loading sample, $\mathrm{Sn}: \mathrm{Rh}=15: 1)$. These results reflected that charge transfer tendency from $\mathrm{Rh}$ atom to $\mathrm{Sn}$ atom became stronger when the concentration of $\mathrm{Sn}$ increased. In these samples, Rh site was more positively charged, which might lead to more effective 6 
charge separation in photo-induced hydrogen generation.

Generally, hydrogen evolution reaction involves the five processes: (1) $\mathrm{H}^{+}$ chemisorption; (2) chemisorbed $\mathrm{H}^{+}$was reduced by excited electron to form $\mathrm{H}$ atom; (3) freshly formed $\mathrm{H}$ atom diffusion from $\mathrm{H}$ atom formation site to neighbor active site; (4) forming fresh hydrogen molecule by $\mathrm{H}-\mathrm{H}$ recombination; (5) hydrogen desorption. Among them, the chemisorbed $\mathrm{H}$ recombination might be the rate-determining step [18-19]. Therefore, it is reasonable to suppose that the recombination of chemisorbed $\mathrm{H}$ is determined by the distance between adjacent chemisorbed sites located on the co-catalyst surface. The surface geometry became important in the formation of fresh hydrogen. When the distance of neighbor chemisorbed site for $\mathrm{H}$ is within a reasonable distance $\left(\mathrm{d}_{\mathrm{H}-\mathrm{H}}<1.8 \AA\right.$ ) [20], the chemisorbed $\mathrm{H}$ recombination probably becomes easy. All the geometry models of hydrogen molecular chemisorption on neighboring $\mathrm{Rh}$ sites were shown in Fig. 7 (A), the recombination of chemisorbed $\mathrm{H}$ may undergo in three possible surface transit states: $\angle \mathrm{HRhRh}>90^{\circ}, \angle \mathrm{HRhRh}=90^{\circ}$ and $0^{\circ}<\angle \mathrm{HRhRh}<90^{\circ}$. Since the bond lengths of $\mathrm{r}_{\mathrm{Rh}-\mathrm{H}}$ and $\mathrm{d}_{\mathrm{H}-\mathrm{H}}$ are $1.43 \AA$ [21] and $1.8 \AA$, respectively, the $\mathrm{r}_{\mathrm{Rh}-\mathrm{Rh}}$ must be less than $4.66 \AA$ for the chemisorbed $\mathrm{H}$ recombination. In the typical Rh crystal, only the types of $\mathrm{r}_{\mathrm{Rh2} 2 \mathrm{Rh} 1}(2.69 \AA)$, $\mathrm{r}_{\mathrm{Rh} 2 \mathrm{-Rh} 3}(3.80 \AA)$ and $\mathrm{r}_{\mathrm{Rh} 1-\mathrm{Rh} 12}(2.69 \AA)$ were suitable. In this case, because of too strong interaction between chemisorbed $\mathrm{H}$ and $\mathrm{Rh}$ atom, the chemisorbed $\mathrm{H}$ diffusion between $\mathrm{Rh}$ atoms was inhibited in some extend. So it is difficult to reach the suitable sites for H-H recombination, which might lead to low activity. However, when neighbor Sn atom was created, as shown in Fig. 7 (B), the chemisorbed $\mathrm{H}$ recombination followed different three models. Because of the bond lengths of $\mathrm{r}_{\mathrm{Sn}-\mathrm{H}}(1.94 \AA)[22]$ and $\mathrm{d}_{\mathrm{H}-\mathrm{H}}(<1.8 \AA)$, so the $\mathrm{r}_{\mathrm{Sn}-\mathrm{Sn}}$ must be less than $5.68 \AA$ for the chemisorbed $\mathrm{H}$ recombination, and in the $\mathrm{SnO}_{2}$ cell, the types of $\mathrm{r}_{\mathrm{Sn} 1-\mathrm{Sn} 2}(4.74 \AA$ ), $\mathrm{r}_{\mathrm{Sn1}-\mathrm{Sn} 4}(3.19 \AA)$ and $\mathrm{r}_{\mathrm{Snn}-\mathrm{Sn} 9}(3.71 \AA)$ were possible surface transit states. However, for chemisorbed $\mathrm{H}$ recombination, $\mathrm{SnO}_{2}$ showed weak ability than $\mathrm{Rh}$, due to its weak $\mathrm{H}^{+}$ chemisorption ability, so it is hard to form reduced $\mathrm{H}$ atom, leading to low activity for hydrogen generation. For $\mathrm{RhSn}_{\mathrm{x}} \mathrm{O}_{\mathrm{y}}$ co-catalyst, $\mathrm{H}^{+}$was first chemisorbed on $\mathrm{Rh}$ sites, then was reduced to form fresh $\mathrm{H}$, and migrated to $\mathrm{Sn}$ atoms for recombination to form hydrogen molecules. Then hydrogen molecules desorption finished over Sn sites. If the 7 
hydrogen formation follows this process, the distribution of $\mathrm{Rh}$ atom in $\mathrm{RhSn}_{\mathrm{x}} \mathrm{O}_{\mathrm{y}}$ co-catalyst will determine the activity of hydrogen evolution. As the results shown in Fig. 7 (C), the spacing of $\mathrm{Rh}$ atoms increased as the $\mathrm{Sn}$ amount increase, the TON showed very good linear dependence on $\mathrm{d}_{\mathrm{Rh}-\mathrm{Rh}}$ in different $\mathrm{RhSn}_{\mathrm{x}} \mathrm{O}_{\mathrm{y}}$ co-catalysts. The TONs of hydrogen evolution dependence on Sn-Rh ratio were also given in Table 1. The TON of $\mathrm{RhSn}_{\mathrm{x}} \mathrm{O}_{\mathrm{y}}$ co-catalyst increased with the amount of Sn specie. And the highest value (64.0) was achieved at 10: 1 of the atomic ratio (Sn: $\mathrm{Rh})$.

The hydrogen evolution stability of $\mathrm{RhSn}_{\mathrm{x}} \mathrm{O}_{\mathrm{y}}$ was tested as shown in Fig. 8. The results indicated that the $\mathrm{RhSn}_{\mathrm{x}} \mathrm{O}_{\mathrm{y}}$ co-catalyst showed the high stability for hydrogen evolution reaction. In the first run, the $\mathrm{RhSn}_{\mathrm{x}} \mathrm{O}_{\mathrm{y}}$ co-catalyst showed excellent activity. However, the activity gradually reduced in the next two runs, due to the consumption of TEOA and EY. In the fifth run, $\mathrm{RhSn}_{\mathrm{x}} \mathrm{O}_{\mathrm{y}}$ co-catalyst was collected from the reaction mixture by centrifuging, after adding fresh EY and TEOA, the activity was renewed and its activity was 1.4 times higher than that of the first run. The lower activity in the first run might due to the induction period.

The reaction mechanism of hydrogen evolution was proposed in scheme 1. During the reaction process, $\mathrm{EY}$ absorbed photons to form singlet excited state $\mathrm{EY}^{1^{*}}$, and then produced the lowest-lying triplet excited state $\mathrm{EY}^{3^{*}}$ via an efficient intersystem crossing. $\mathrm{EY}^{3^{*}}$ could be reductively quenched by TEOA and produce $\mathrm{EY}^{\bullet}$ and oxidative donor $\left(\mathrm{TEOA}^{+}\right)$. By collision, The electron of $\mathrm{EY}^{-\bullet}$ species was transferred to $\mathrm{RhSn}_{\mathrm{x}} \mathrm{O}_{\mathrm{y}}$ co-catalyst to reduce the $\mathrm{H}^{+}$adsorbed on the $\mathrm{Rh}$ atom, and then the $\mathrm{H}$ atoms migrated to $\mathrm{Sn}$ atoms to form hydrogen molecules. At last, the hydrogen molecules desorption finished over Sn sites.

\section{Conclusions}

A novel and stable $\mathrm{RhSn}_{\mathrm{x}} \mathrm{O}_{\mathrm{y}}$ composite oxides co-catalyst was synthesized by in situ chemical deposition via Eosin Y photosensitizer under visible light irradiation at $\mathrm{pH} 7$. The reactive sites were adjusted by different $\mathrm{Sn}$ and $\mathrm{Rh}$ ration, which led to excellent photocatalytic performance and stability for hydrogen evolution. When the atomic ratio 
of $\mathrm{Sn}$ to $\mathrm{Rh}$ was $10 / 1$, the hydrogen evolution rate over $\mathrm{RhSn}_{\mathrm{x}} \mathrm{O}_{\mathrm{y}}$ co-catalyst in 60 min was1280.3 $\mu \mathrm{mol} \cdot \mathrm{h}^{-1}$ (corresponding TON 64), which was 8.3 times than that of $\mathrm{Rh}$ sample without the Sn, and the highest apparent quantum efficiency (AQE) reached $21.0 \%$ at $430 \mathrm{~nm}$. Based on the XRD and XPS characterizations, the $\mathrm{Rh}$ atom arrangement on the $\mathrm{RhSn}_{\mathrm{x}} \mathrm{O}_{\mathrm{y}}$ co-catalyst surface were achieved to future adjust the interaction between $\mathrm{Rh}$ and $\mathrm{Sn}$. By adjusting this interaction, more efficient the excited charge separation and transfer from $\mathrm{Rh}$ atom to $\mathrm{Sn}$ atom was fulfilled, leading to more effective photo-induced hydrogen generation.

\section{Acknowledgment}

This work is supported by the 973 and 863 Programs of Department of Sciences and Technology of China (2013CB632404, 2012AA051501) and the NSF of China (Grant No. 21173242 and 21433007), respectively. 


\section{REFERENCES}

[1] Crabtree RH, Mihelcic JM, Quirk JM. Iridium Complexes in Alkane Dehydrogenation. J Am Chem Soc 1979; 101, 7738-40.

[2] Yang Y, Xia L F, Fan Z Y, Chen W, Chen X P, Yuan J, Shangguan W F. Preparation of nano copper with high dispersion and its photocatalytic hydrogen production on $\mathrm{Cu} / \mathrm{TiO}_{2}$. J Mol Catal (China) 2014; 28, 182-87.

[3] Crabtree RH, Mellea MF, Mihelcic JM, Quirk JM. Alkane Dehydrogenation by Iridium Complexes. J Am Chem Soc 1982; 104, 107-13.

[4] Peng S Q, Ding M, Yi T, Li Y X. Photocatalytic hydrogen evolution in the presence of pollutant methylamines over $\mathrm{Pt} / \mathrm{ZnIn}_{2} \mathrm{~S}_{4}$ under visible light irradiation. J Mol Catal (China) 2014; 28, 466-73.

[5] Zhou W, Hu X L, Zhao X R, Jia M K, Huang Y P, Fang Y F. Preparation of graphene-BiOBr composite and the enhanced photocatalytic activity under visible-light irradiation. J Mol Catal (China) 2014; 28, 367-75.

[6] Kumar N, Monga PS, Biswas A K, Das A. Modeling and Simulation of Clean Fuel Production by Enterobacter Cloacae IIT-BT 08. Int J Hydrogen Energy 2000; 25, 945-52.

[7] Jasimuddin S, Yamada T, Fukuju K, Otsuki J, Sakai K. Photocatalytic Hydrogen Production from Water in Self-assembled Supramolecular Iridium-cobalt systems. Chem Commun 2010; 46, 8466-68. 
[8] McLaughlin MP, McCormick TM, Eisenberg R, Holland PL.A Stable Molecular Nickel Catalyst for the Homogeneous Photogeneration of Hydrogen in Aqueous Solution. Chem Commun 2011; 47, 7989-91.

[9] Bigi JP, Hanna TE, Harman WH, Changa A, Chang CJ. Electrocatalytic Reduction of Protons to Hydrogen by A Water-compatible Cobalt Polypyridyl Platform. Chem Commun 2010; 46, 958-60.

[10] Min S, Lu G. Sites for High Efficient Photocatalytic Hydrogen Evolution on a Limited-Layered $\mathrm{MoS}_{2}$ Cocatalyst Confined on Graphene Sheets-The Role of Graphene. J Phys Chem C 2012; 116, 25415-24.

[11] Min S, Lu G. Dye-Sensitized Reduced Graphene Oxide Photocatalysts for Highly Efficient Visible-Light-Driven Water Reduction. J Phys Chem C 2011; 115, 13938-45.

[12] Min S, Lu G. Enhanced Electron Transfer from the Excited Eosin Y to mpg- $\mathrm{C}_{3} \mathrm{~N}_{4}$ for Highly Efficient Hydrogen Evolution under 550 nm Irradiation. J Phys Chem C 2012; 116, 19644-52.

[13] Yan H, Yang J, Ma G, Wu G, Zong X, Lei Z, Shi J, Li C. Visible-light-driven Hydrogen Production with Extremely High Quantum Efficiency on Pt-PdS/CdS Photocatalyst. J Catal 2009; 266, 165-68.

[14] Kong C, Min S, Lu G. Dye-sensitized Cobalt catalysts for High Efficient Visible Light Hydrogen Evolution. Int J Hydrogen Energy 2014; 39, 4836-44.

[15] Kong C, Min S, Lu G. A novel amorphous $\mathrm{CoSn}_{x} \mathrm{O}_{\mathrm{y}}$ decorated grapheme nanohybrid photocatalyst for highly efficient photocatalytic hydrogen evolution. Chem Commun 2014; 50, 5037-39. 
[16] Kong C, Min S, Lu G. Robust Pt-Sn Alloy Decorated Graphene Nanohybrid Cocatalyst for Photocatalytic Hydrogen Evolution. Chem Commun 2014; 50, 9281-83.

[17] Shimidzu T, Iyoda T, Koide Y. An Advanced Visible-Light-Induced Water Reduction with Dye-Sensitized Semiconductor Powder Catalyst. J Am Chem Soc 1985; 107, 35-41.

[18] Marković N, Grgur B, Ross P. Temperature Dependent Hydrogen Electrochemistry on Platinum Low-Index SingleCrystal Surfaces in Acid Solutions. J Phys Chem B 1997; 101, 5405-13.

[19] Skúlason E, Karlberg G, Rossmeisl J, Bligaard T, Greeley J, Jónsson H, Nørskov J. Density Functional Theory Calculations for the Hydrogen Evolution Reaction in an Electrochemical Double Layer on the Pt(111) Electrode. Phys Chem Chem Phys 2007; 9, 3241- 50.

[20] Méndez-Camacho R, Guirado-López RA. Adsorption and Diffusion of Hydrogen on $\mathrm{C}_{60}{ }^{-}$Supported $\mathrm{Pt}_{\mathrm{n}}$ Clusters. J Phys Chem C 2013; 117, 10059-69.

[21] Dorta R, Stevens ED, Nolan SP. Double C-H Activation in a Rh-NHC Complex Leading to the Isolation of a 14-Electron Rh(ш) Complex. J Am Chem Soc 2004; 126, 5054-55.

[22] Eric R, Roland C, Robert FW, Yang P. Isomeric Forms of Heavier Main Group Hydrides: Experimental and Theoretical Studies of the $[\mathrm{Sn}(\mathrm{Ar}) \mathrm{H}]_{2}(\mathrm{Ar}=$ Terphenyl) System. J Am Chem Soc 2007; 129, 16197-08. 


\section{Scheme and Figure Captions}

Fig.1 Hydrogen evolution from EY $\left(1.0 \times 10^{-3} \mathrm{~mol} / \mathrm{L}\right)$ photosensitized systems catalyzed by different atomic ratios of $\mathrm{Sn}: \mathrm{Rh}$ (the amount of $\mathrm{Rh}$ is constant, $20 \mu \mathrm{mol}$ ): (1) $0: 1$, (2) 1: 1, (3) 5: 1, (4) 10:1, (5) 15:1, (6) 20:1, (7) 1: 0, (8) $\mathrm{Rh}_{2} \mathrm{O}_{3}$ in $100 \mathrm{ml}$ of $10 \%(\mathrm{v} / \mathrm{v})$ triethanolamine (TEOA) aqueous solution $(\mathrm{pH}=7)$ under visible light irradiation $(\lambda \geq 420 \mathrm{~nm})$.

Fig.2 Hydrogen evolution from EY $\left(1.0 \times 10^{-3} \mathrm{~mol} / \mathrm{L}\right)$ photosensitized systems catalyzed by different quantity of $\mathrm{RhSn}_{\mathrm{x}} \mathrm{O}_{\mathrm{y}}$ co-catalyst (the atomic ratio of $\mathrm{Sn}: \mathrm{Rh}$ is 10: 1) in 100 $\mathrm{ml}$ of $10 \%(\mathrm{v} / \mathrm{v})$ triethanolamine $(\mathrm{TEOA})$ aqueous solution $(\mathrm{pH}=7)$ under visible light irradiation $(\lambda \geq 420 \mathrm{~nm})$. 
Fig.3 (A) Effect of $\mathrm{pH}$ on photocatalytic activity of $\mathrm{RhSn}_{\mathrm{x}} \mathrm{O}_{\mathrm{y}}$ co-catalyst for hydrogen evolution; (B) AQEs of hydrogen evolution for EY $\left(1.0 \times 10^{-3} \mathrm{~mol} / \mathrm{L}\right)$ photosensitized systems catalyzed by the $\mathrm{RhSn} \mathrm{n}_{\mathrm{x}} \mathrm{O}_{\mathrm{y}}$ co-catalyst. The system was irradiated by a $300 \mathrm{~W} \mathrm{Xe}$ lamp with a cutoff filter of $420 \mathrm{~nm}$ and a band-pass filter.

Fig.4 Representative XRD patterns: (1) $\mathrm{Rh}$; (2) $\mathrm{SnO}_{2}$; (3), (4), (5), (6) $\mathrm{RhSn}_{\mathrm{x}} \mathrm{O}_{\mathrm{y}}$ co-catalyst with different atomic ratio of $\mathrm{Sn}$ and $\mathrm{Rh}(1: 1,5: 1,10: 1,15: 1$, respectively).

Fig.5 (A) TEM image and (B) HRTEM image for Rh-Sn co-catalyst; (C) HAADF-STEM (high-angle annular dark field scanning transmission electron microscopy) image and elemental mapping images of $\mathrm{RhSn}_{\mathrm{x}} \mathrm{O}_{\mathrm{y}}$ co-catalyst; (D) the distribution of $\mathrm{RhSn}_{\mathrm{x}} \mathrm{O}_{\mathrm{y}}(\mathrm{Sn}: \mathrm{Rh}=10$ : 1)particle size.

Fig.6 (A) Sn 3d XPS spectra of $\mathrm{RhSn}_{\mathrm{x}} \mathrm{O}_{\mathrm{y}}$ co-catalyst (1, 2, 3 and 4 represented the atomic ratios $\mathrm{Sn}$ : Rh were 1: 1, 5:1, 10: 1 and 15: 1, respectively). (B) $\mathrm{Rh} 3 \mathrm{~d}$ XPS spectra of Rh-Sn co-catalyst $(1,2,34$ and 5 represented the atomic ratios of $\mathrm{Sn}: \mathrm{Rh}$ were $1: 0,1: 1,5: 1,10: 1$ and 15: 1, respectively).

Fig.7 Schematic diagram of chemisorbed $\mathrm{H}$ recombination over $\mathrm{Rh}$ atoms (A), $\mathrm{Sn}$ atoms (B) and the relation between TON and the distance of $\mathrm{Rh}-\mathrm{Rh}(\mathrm{C})$.

Table.1 The TON of $\mathrm{RhSn}_{\mathrm{x}} \mathrm{O}_{\mathrm{y}}$ co-catalyst in different atomic ratio ( $\mathrm{Sn}: \mathrm{Rh}$ ).

Fig.8 Stability test of hydrogen evolution over EY-sensitized $\mathrm{RhSn}_{\mathrm{x}} \mathrm{O}_{\mathrm{y}}$ composite oxides. The reaction was continued for $360 \mathrm{~min}$, with evacuation every $60 \mathrm{~min}$ : (1) first run; (2) second run; (3) third run; (4) fourth run;(5) $\mathrm{RhSn}_{\mathrm{x}} \mathrm{O}_{\mathrm{y}}$ co-catalyst was collected by centrifuging from the reaction mixture. The recycled $\mathrm{RhSn}_{\mathrm{x}} \mathrm{O}_{\mathrm{y}}$ co-catalyst was mixed with TEOA solution and fresh EY, and evacuation; (6) sixth run (the black line represent 
$\mathrm{RhSn}_{\mathrm{x}} \mathrm{O}_{\mathrm{y}}$ co-catalyst, the red line represent the system without the specie of $\mathrm{Sn}$ ).

Scheme.1 Proposed photocatalytic mechanism for hydrogen evolution over $\mathrm{RhSn}_{\mathrm{x}} \mathrm{O}_{\mathrm{y}}$ co-catalyst under visible light irradiation. 


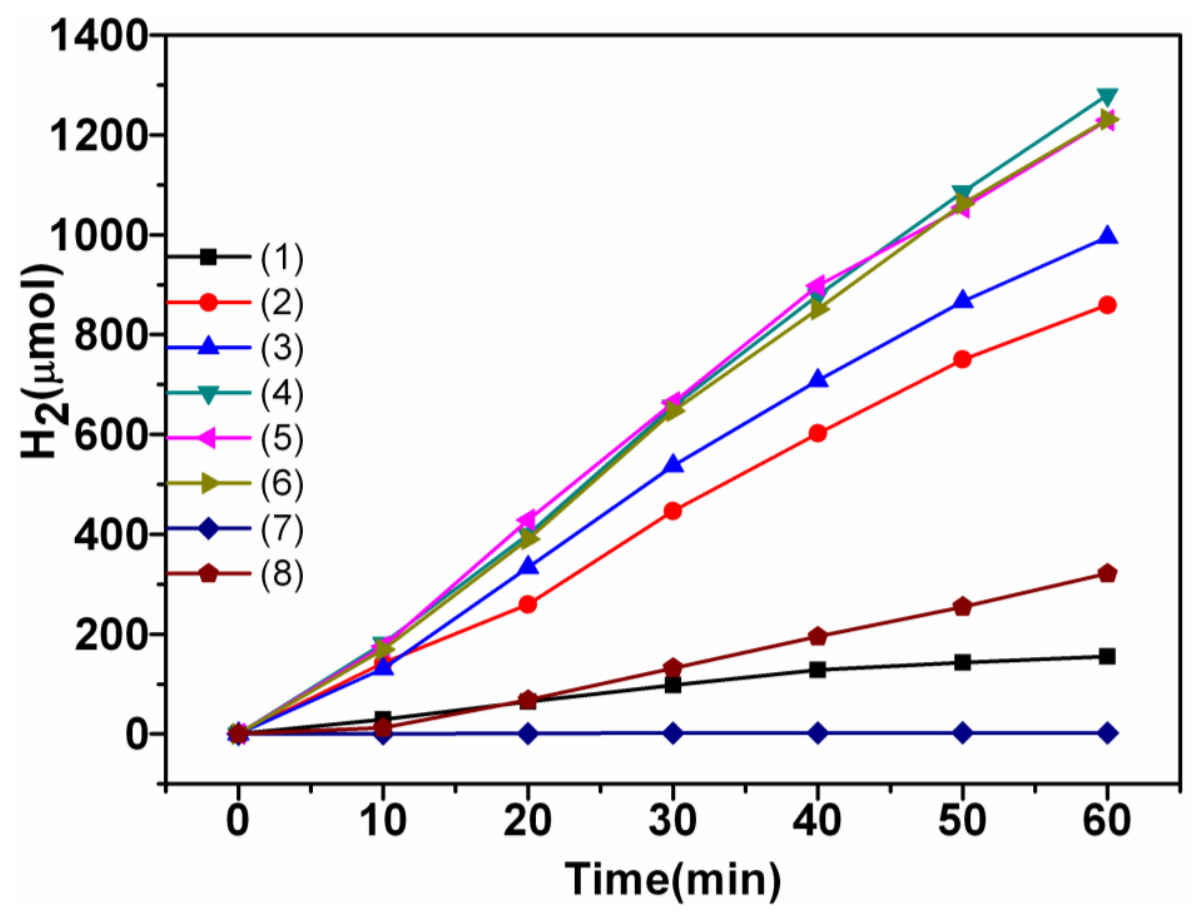

Fig. 1 


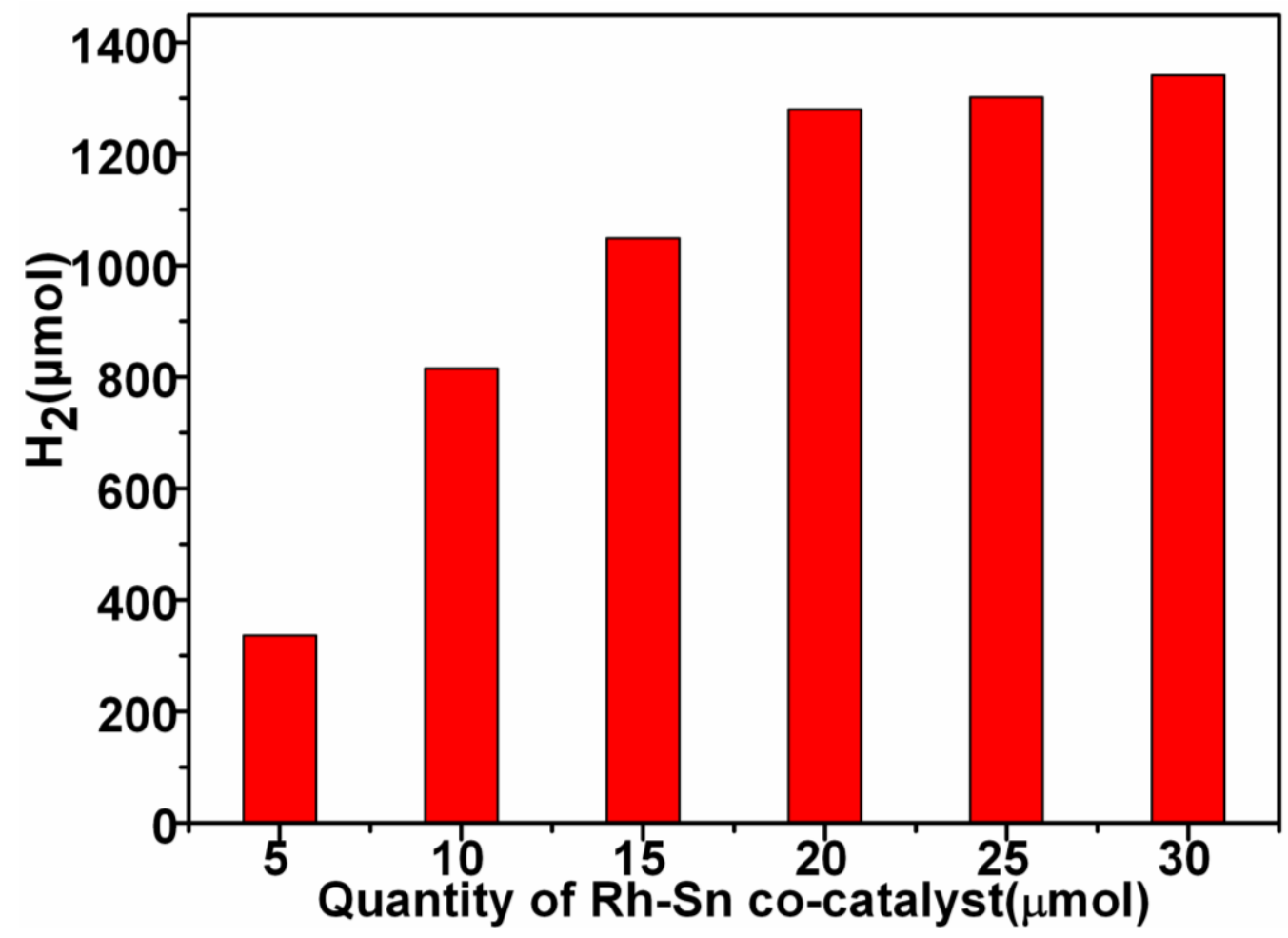

Fig. 2 


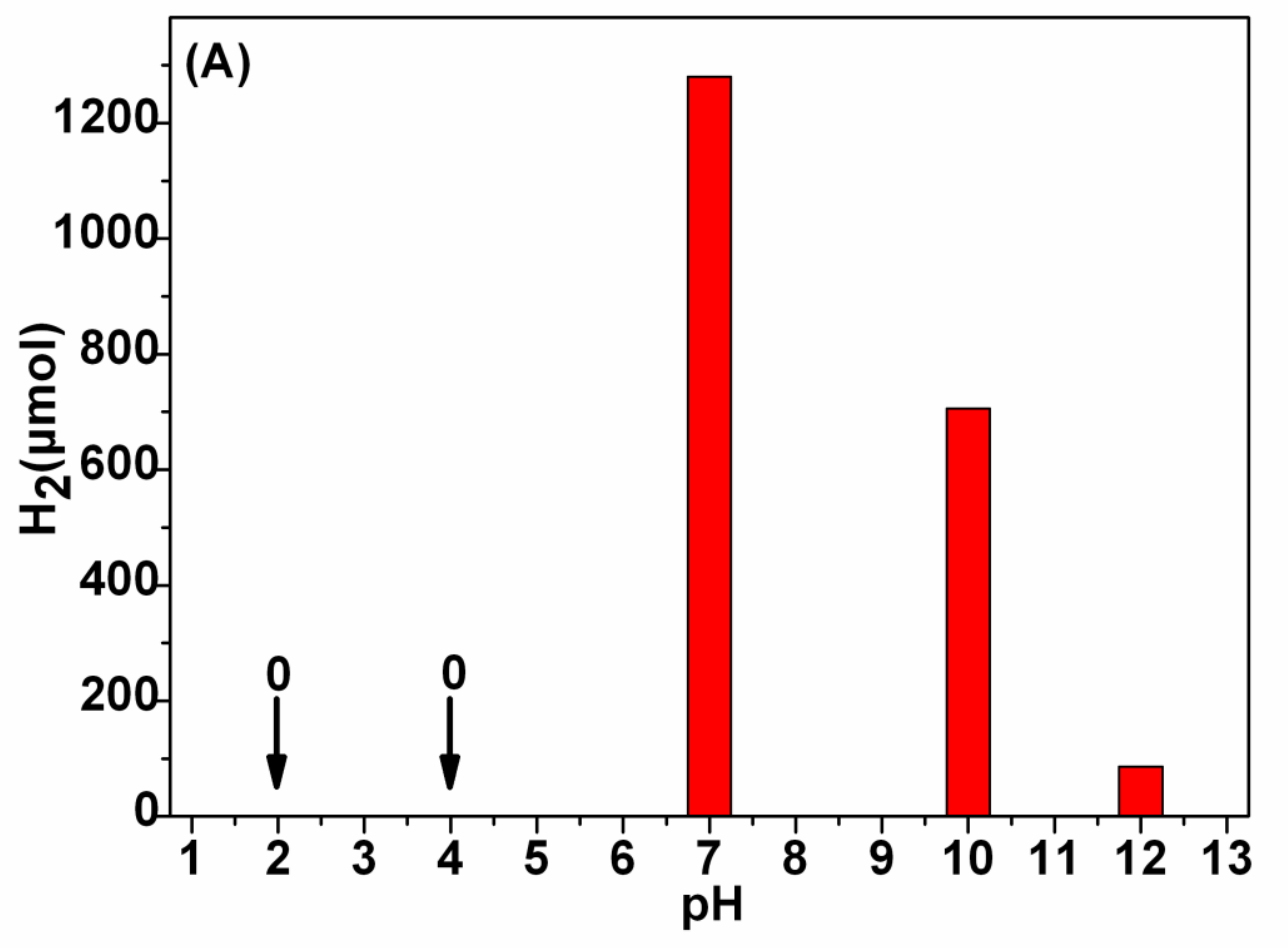

Fig. 3 (A) 


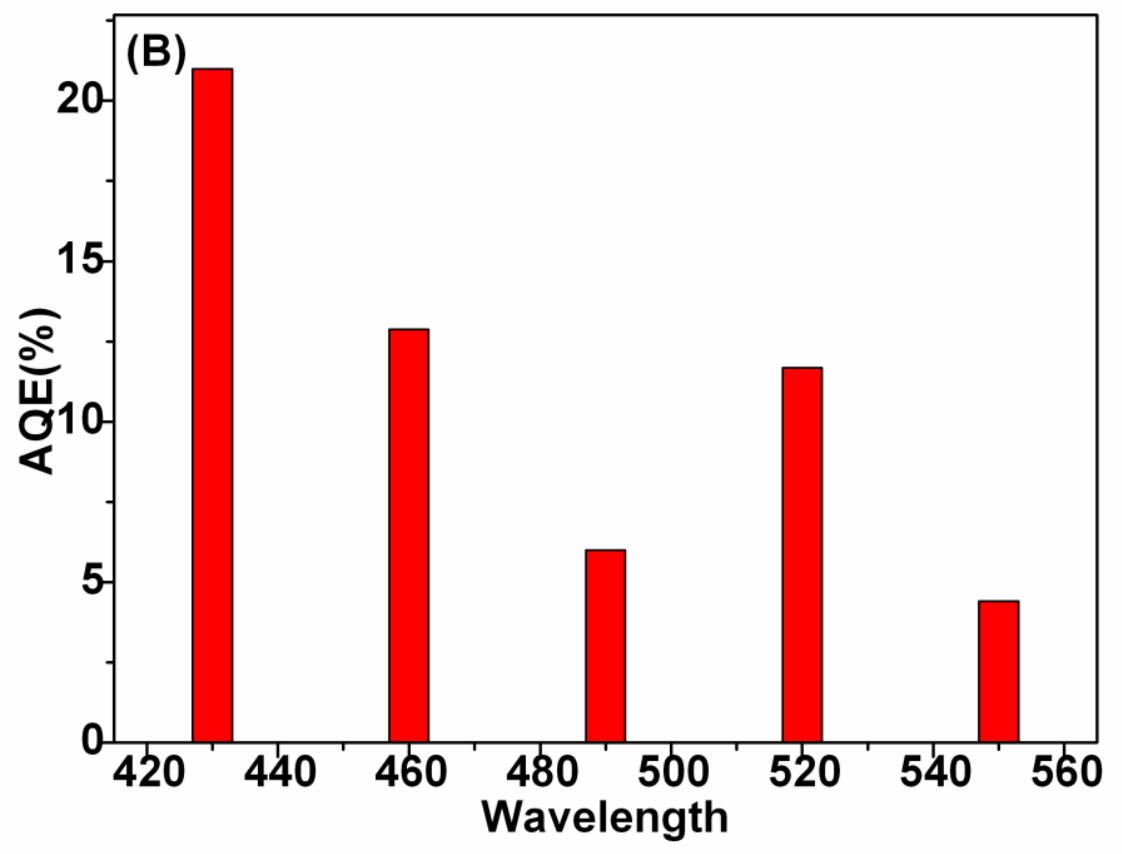

Fig. 3 (B) 


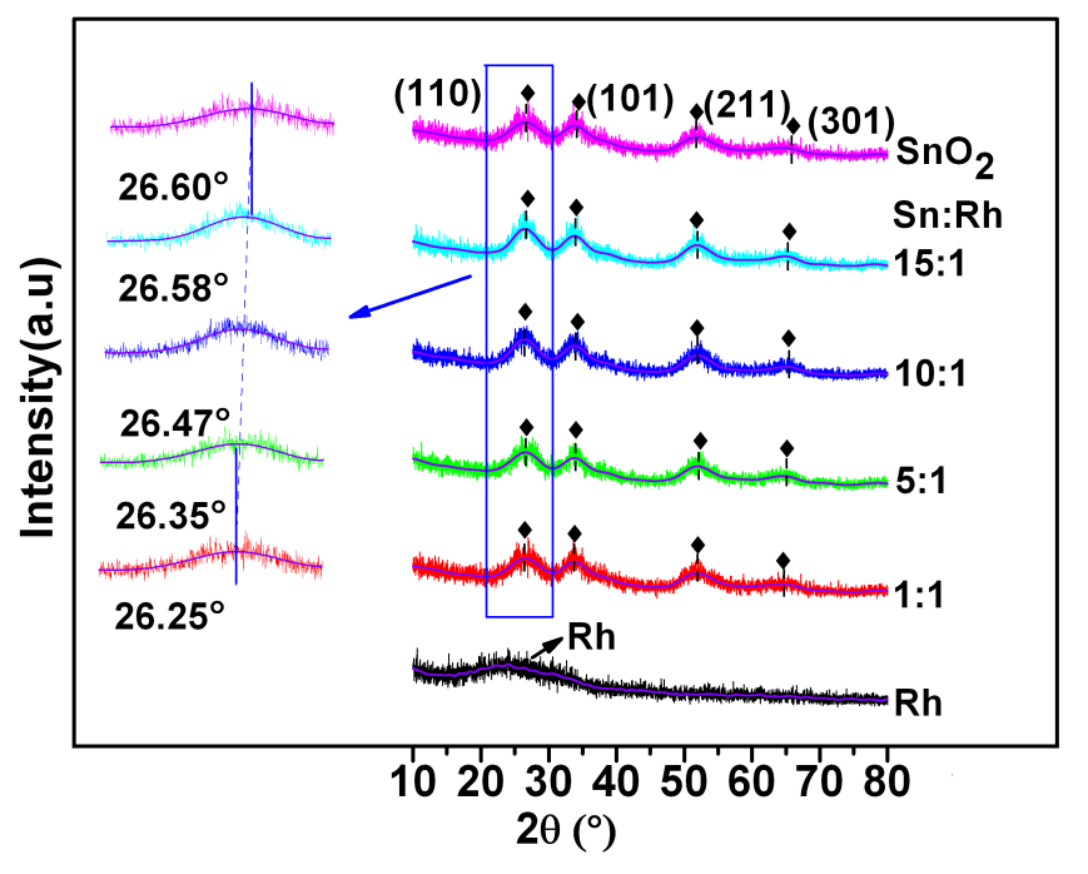

Fig. 4 


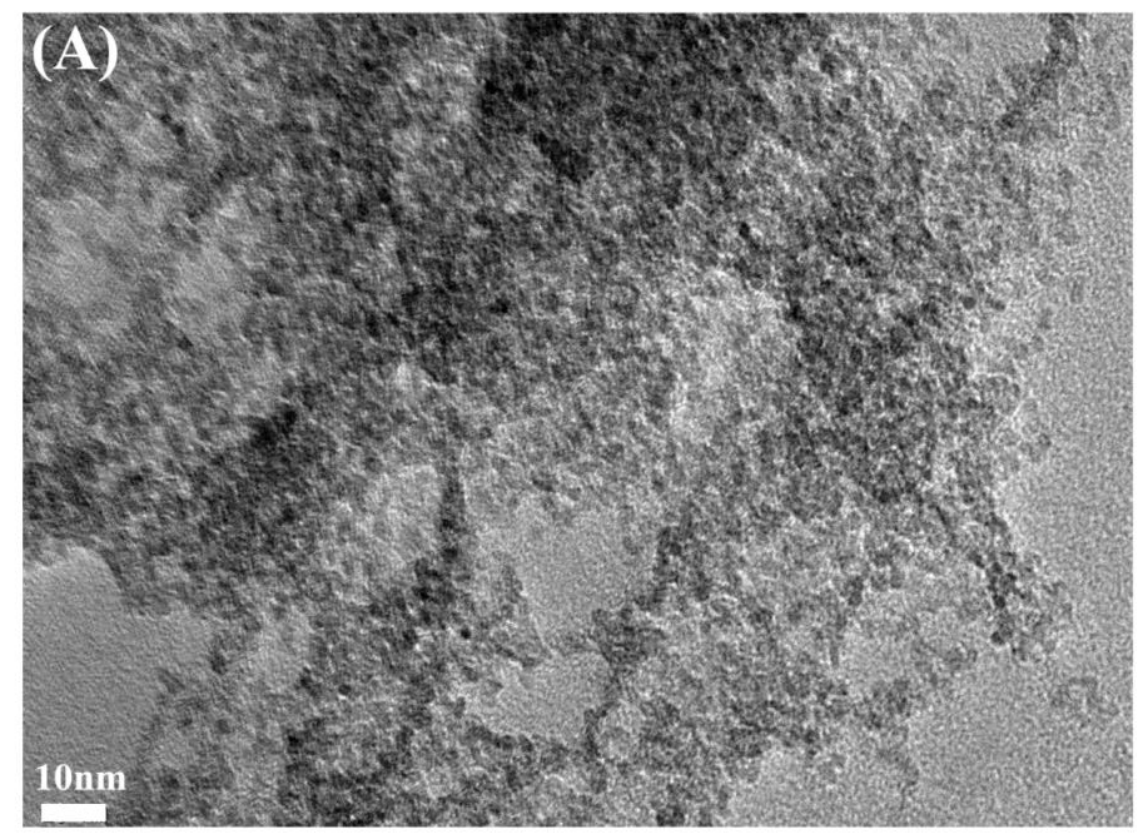

Fig. 5 (A) 


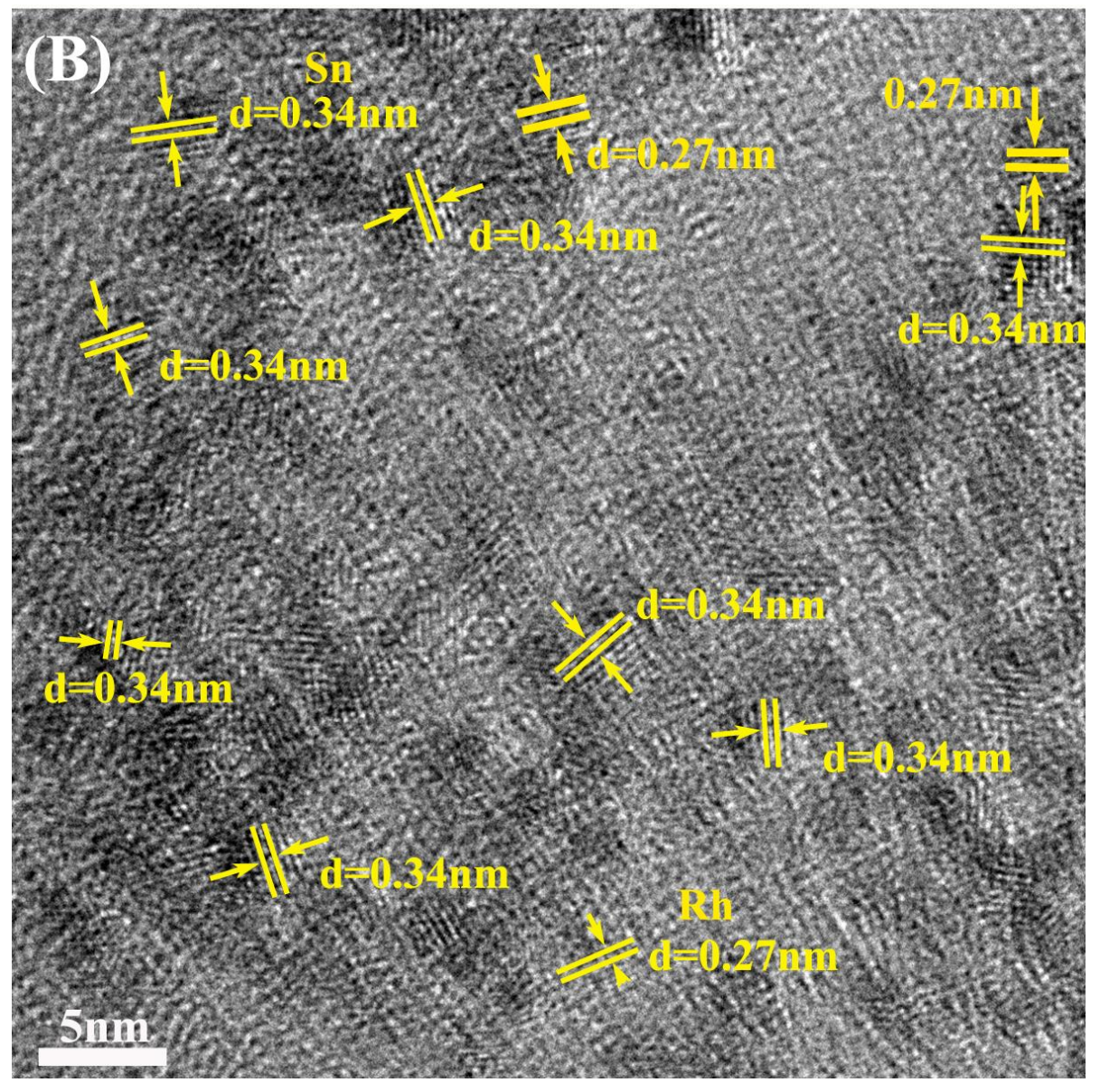

Fig. 5 (B) 


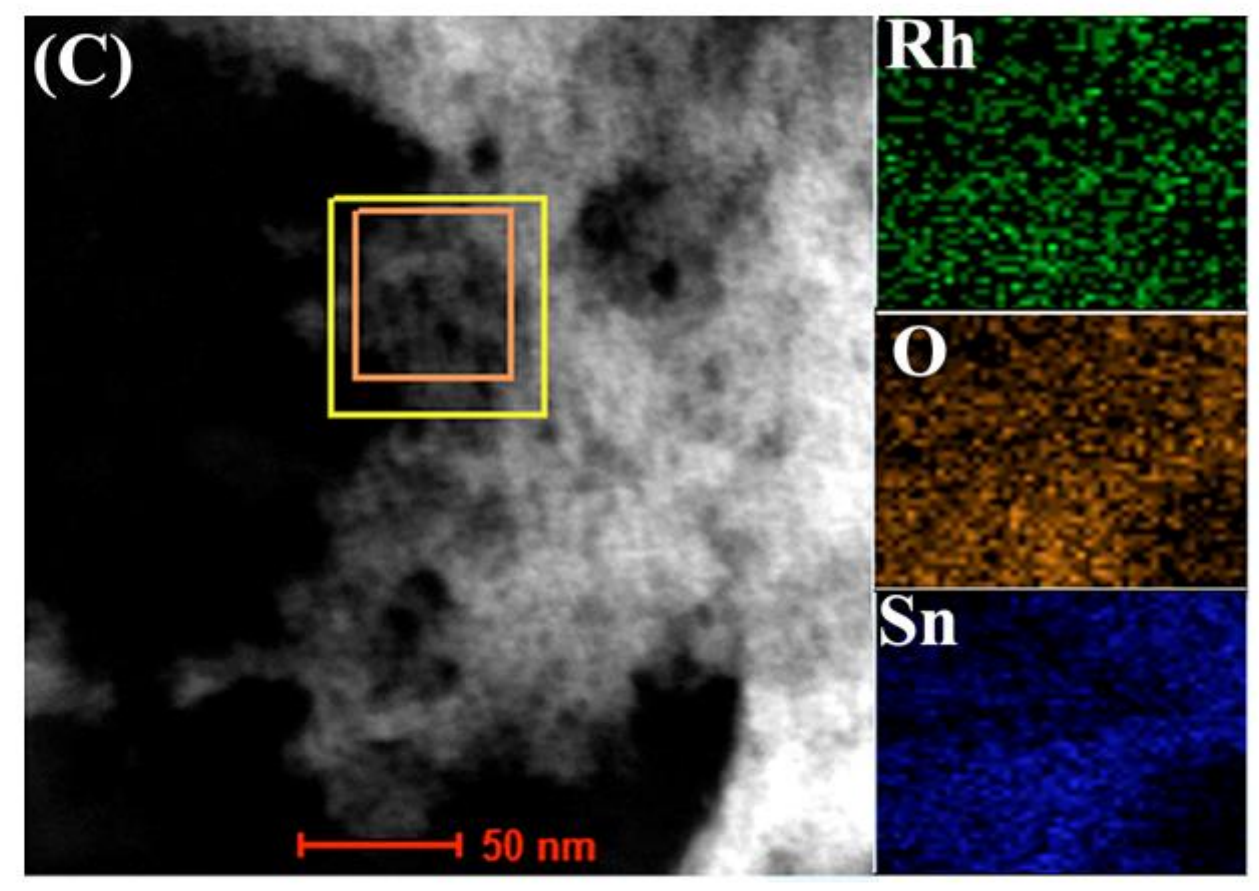

Fig. 5 (C) 


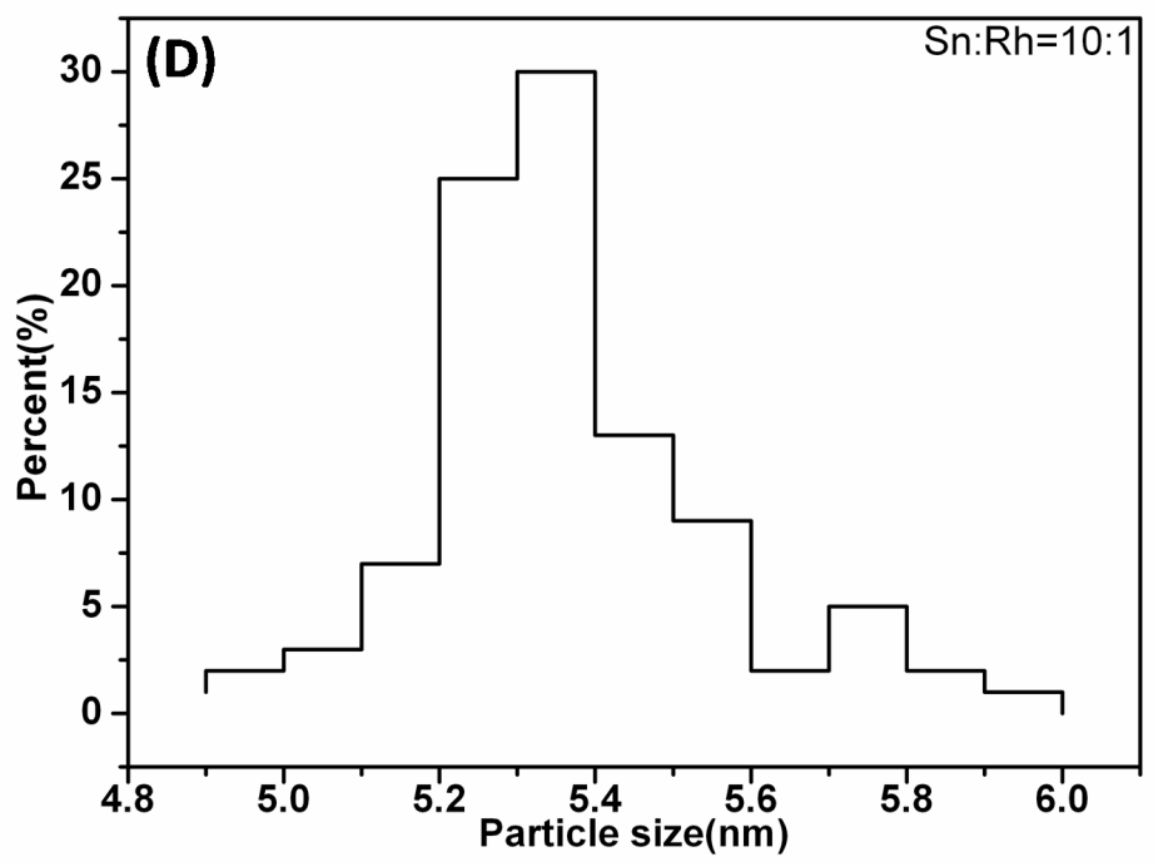

Fig. 5 (D) 


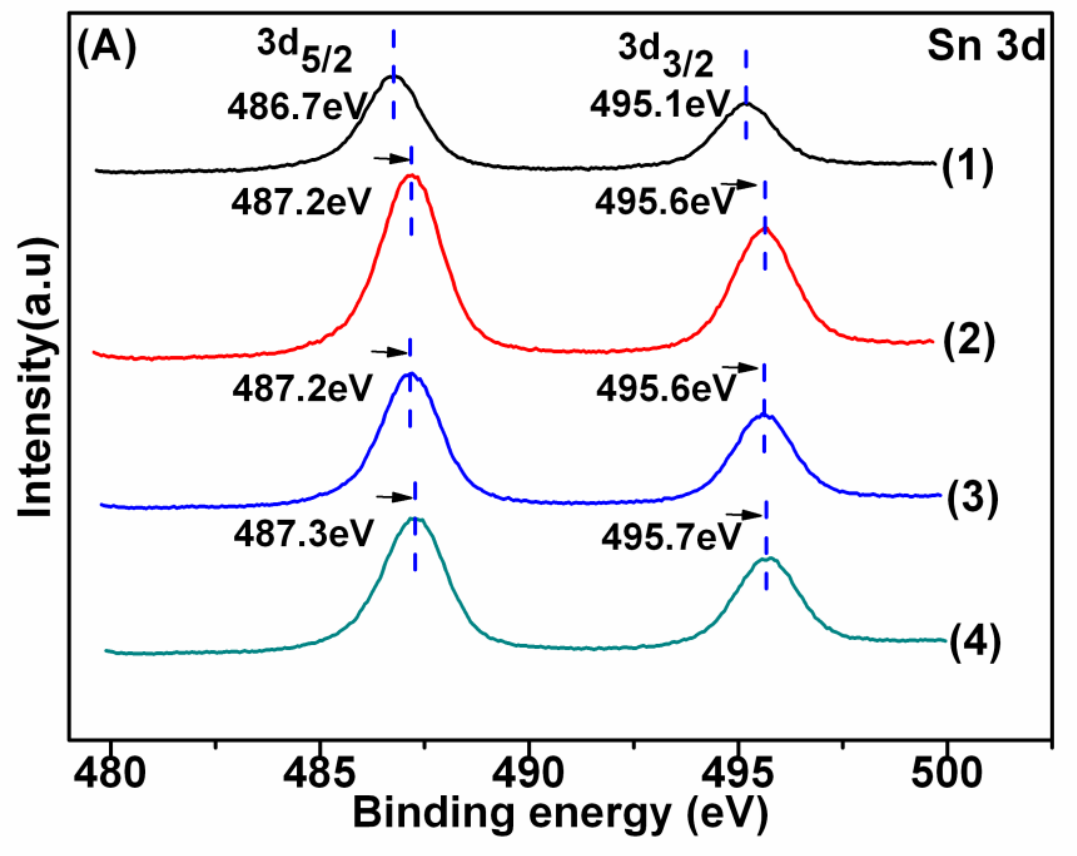

Fig. 6 (A) 


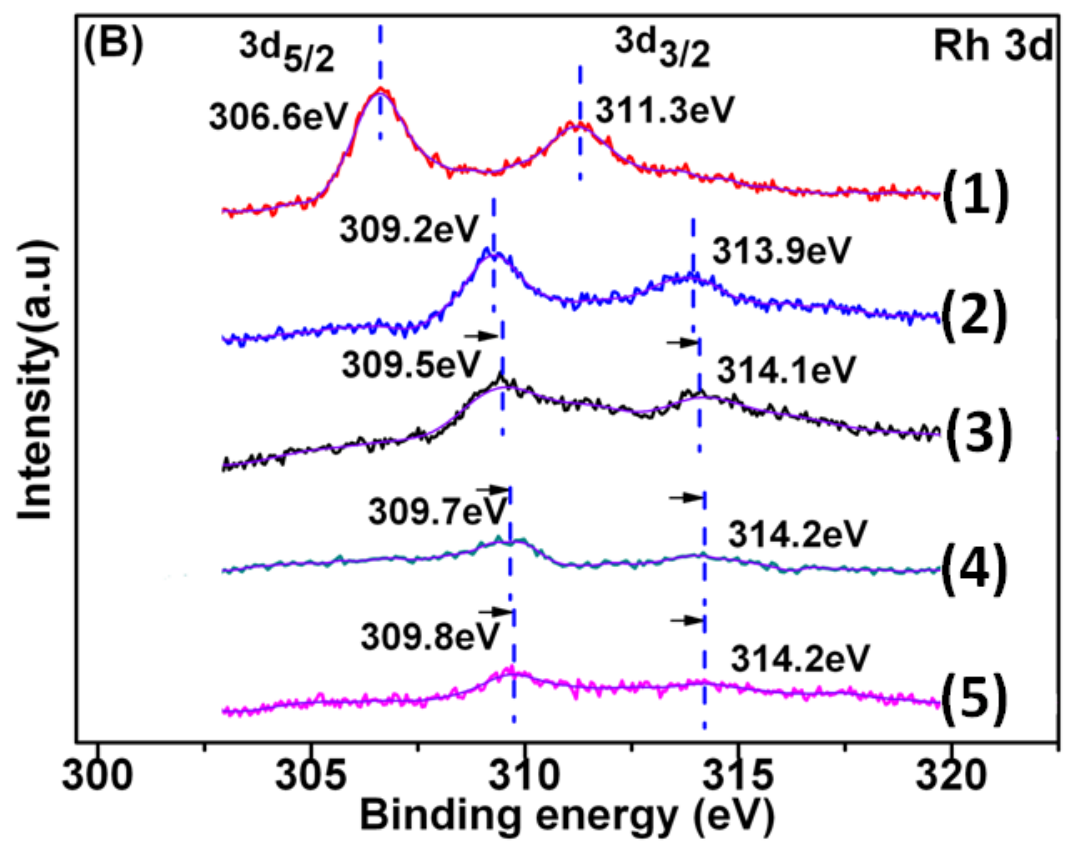

Fig. 6 (B) 

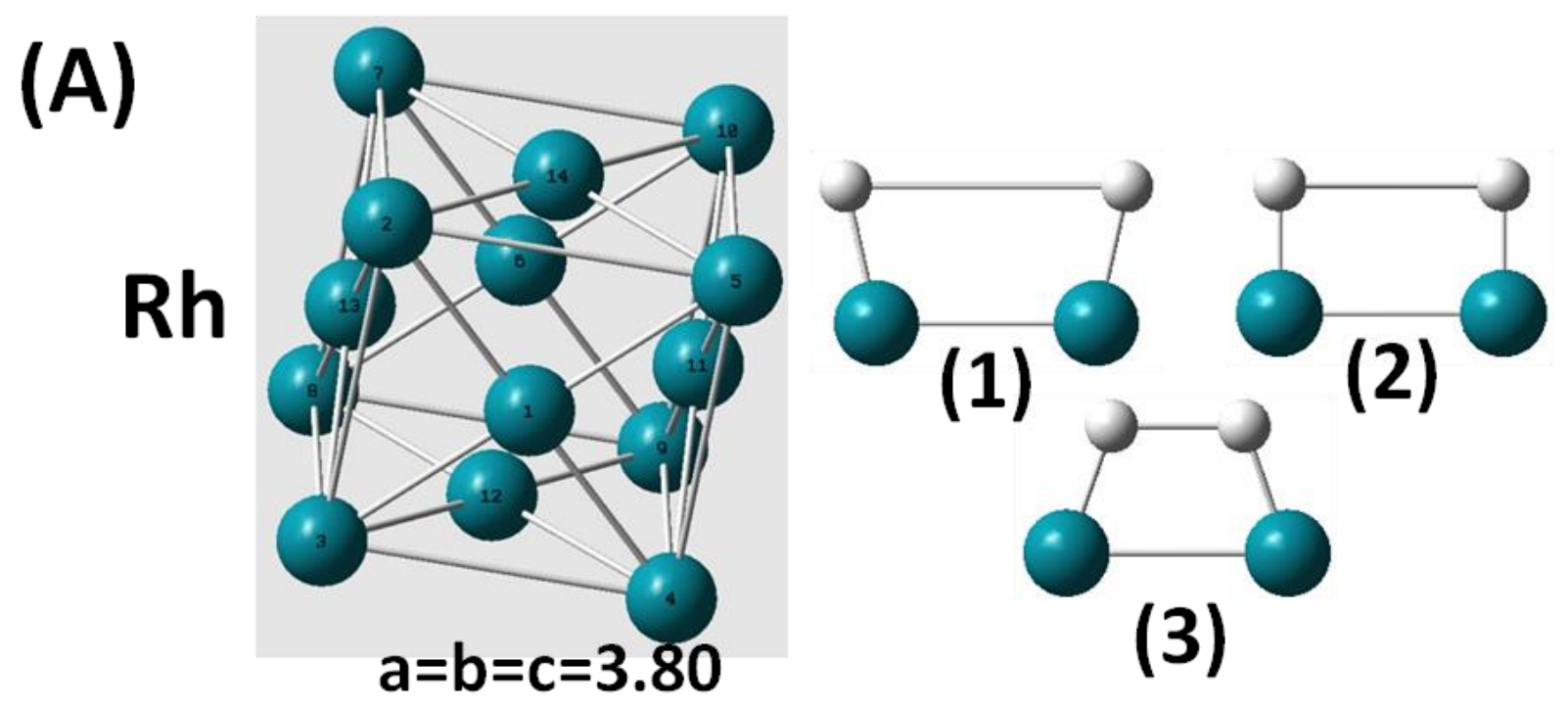

Fig. 7 (A) 


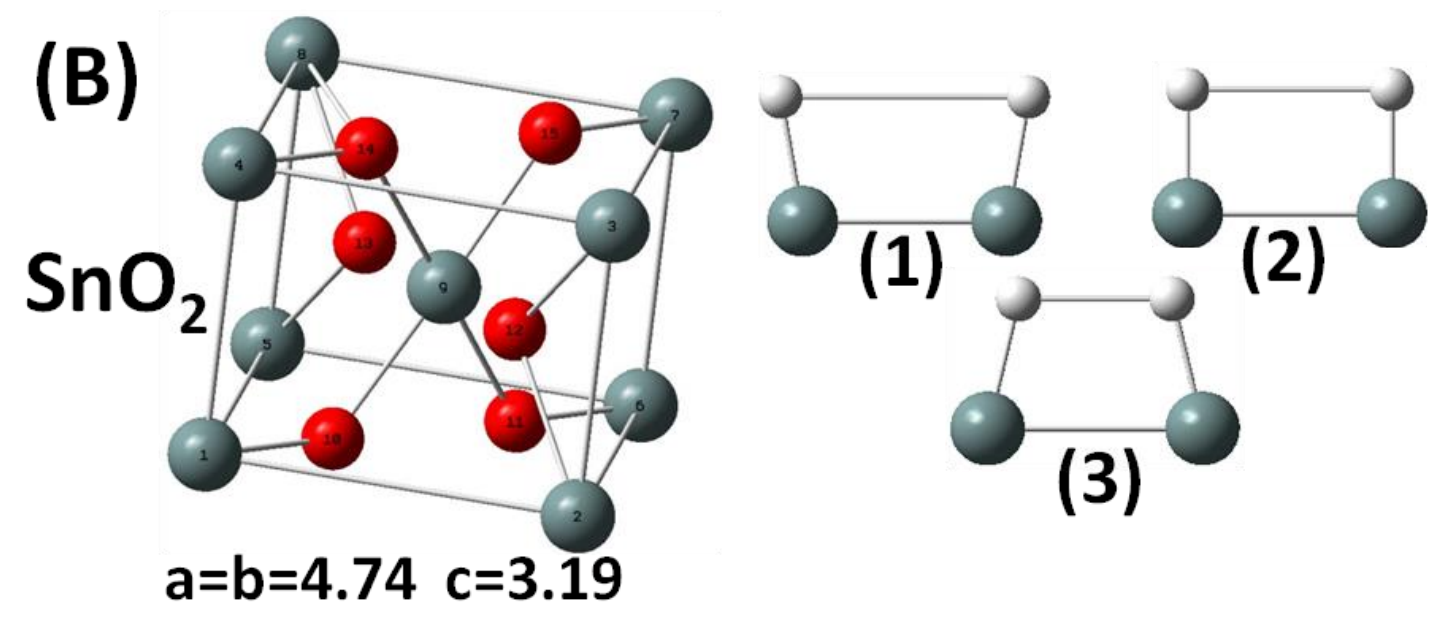

Fig. 7 (B) 


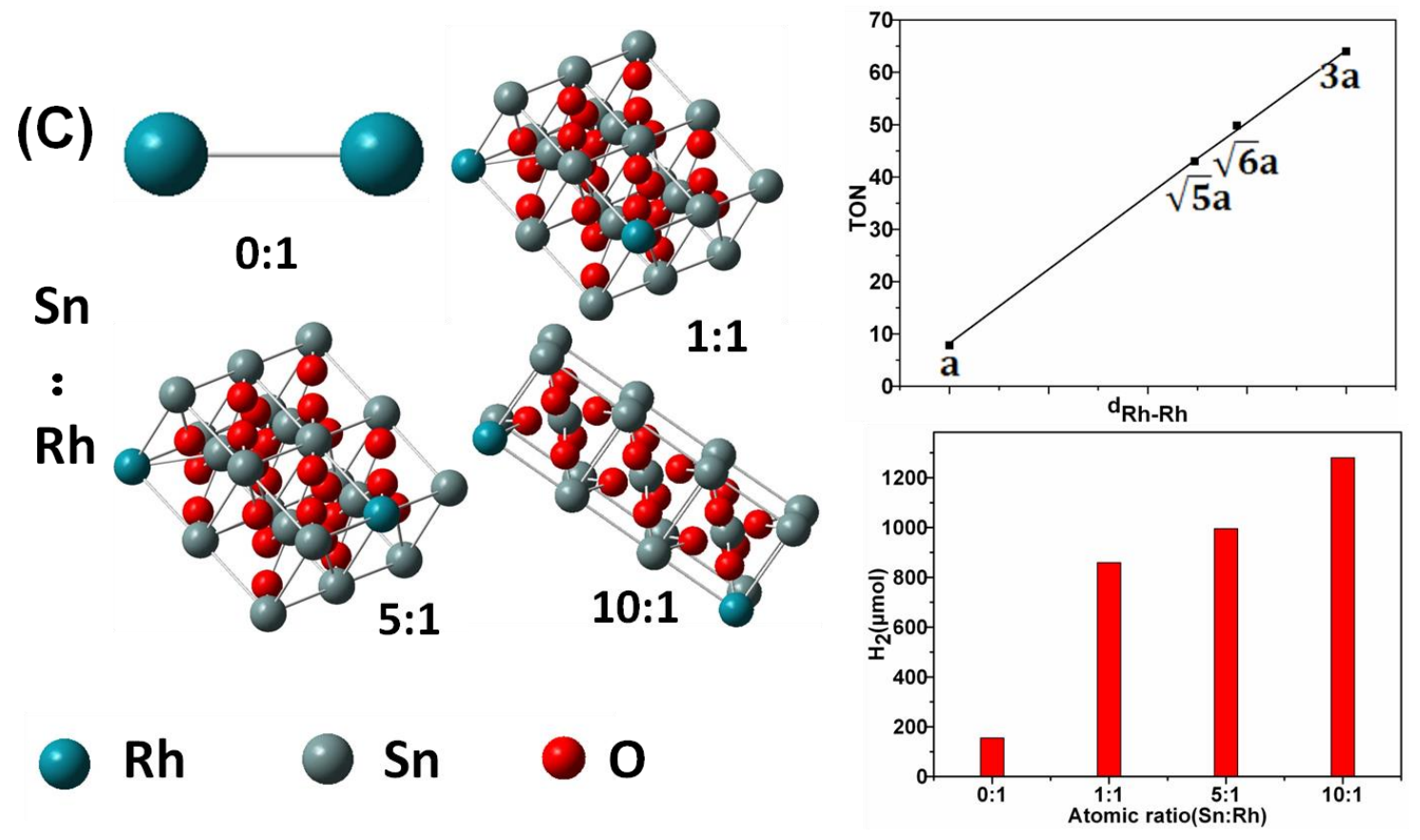

Fig. 7 (C) 
Table 1

\begin{tabular}{cc}
\hline The atomic ratio (Sn:Rh) & TON \\
\hline $1: 0$ & 0.01 \\
$0: 1$ & 7.8 \\
$1: 1$ & 43.0 \\
$5: 1$ & 49.8 \\
$10: 1$ & 64.0 \\
$15: 1$ & 61.5 \\
$20: 1$ & 61.6 \\
\hline
\end{tabular}




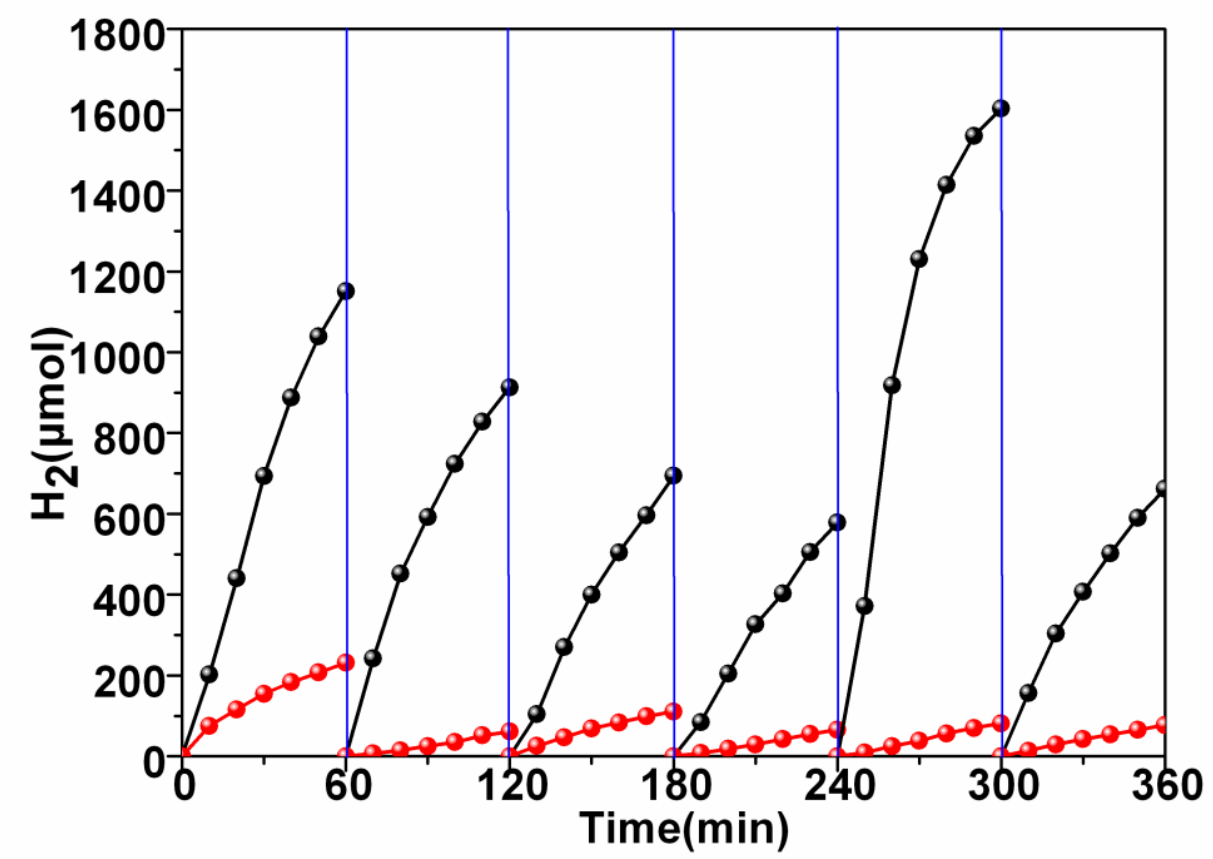

Fig. 8 


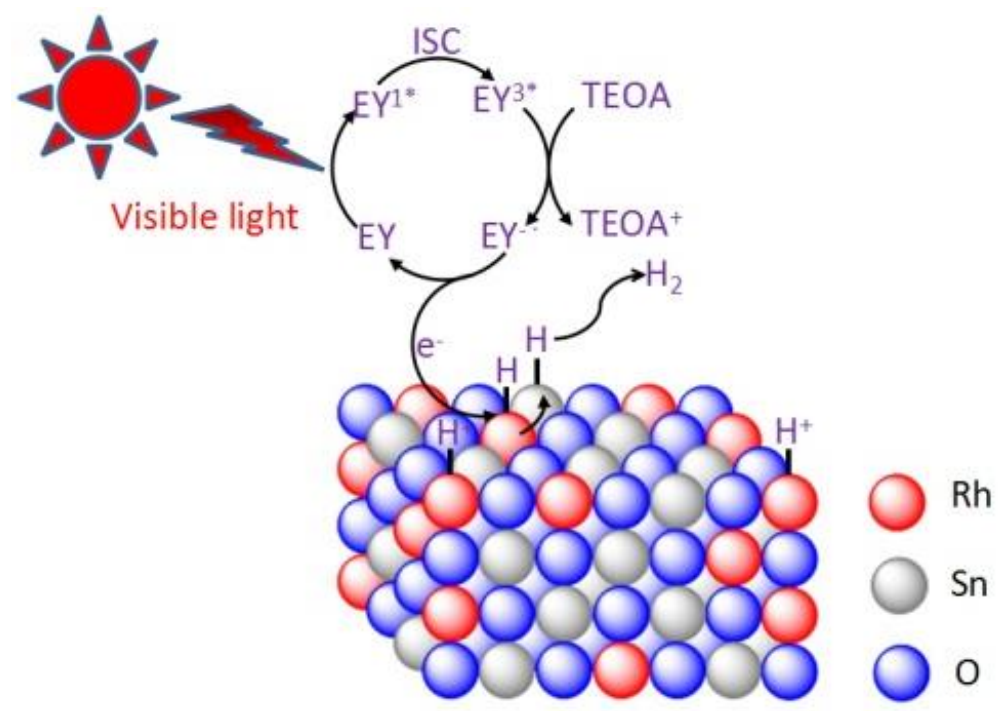

Scheme 1 
Graphic Abstract.

Novel and stable rhodium tin composite oxides $\left(\mathrm{RhSn}_{\mathrm{x}} \mathrm{O}_{\mathrm{y}}\right)$ photocatalyst exhibited higher hydrogen evolution activity than Rh alone. In this work, we studied the modification of surface active site of $\mathrm{RhSn}_{\mathrm{x}} \mathrm{O}_{\mathrm{y}}$ composite oxides co-catalyst by $\mathrm{Sn}$ addition for high efficient photocatalytic hydrogen evolution under visible light irradiation in detail. After sensitized by Eosin Y (EY) dye, the photocatalyst exhibited the apparent quantum efficiency (AQE) of $21.0 \%$ at $430 \mathrm{~nm}$ for hydrogen generation. Under optimized conditions, the highest hydrogen evolution rate of $1280.3 \mu \mathrm{mol} \cdot \mathrm{h}^{-1}$ (corresponding TON 64) was achieved, which was 8.3 times higher than that of Rh co-catalyst alone. The significant activity promotion was accomplished by the adjustment of Rh sites via Sn addition. Based on the XRD and XPS characterizations, the Rh atom arrangement on the $\mathrm{RhSn}_{\mathrm{x}} \mathrm{O}_{\mathrm{y}}$ co-catalyst surface were achieved. By adjusting this interaction, more efficient the excited charge separation and transfer from $\mathrm{Rh}$ atom to $\mathrm{Sn}$ atom was fulfilled, leading to more effective photo-induced hydrogen generation.

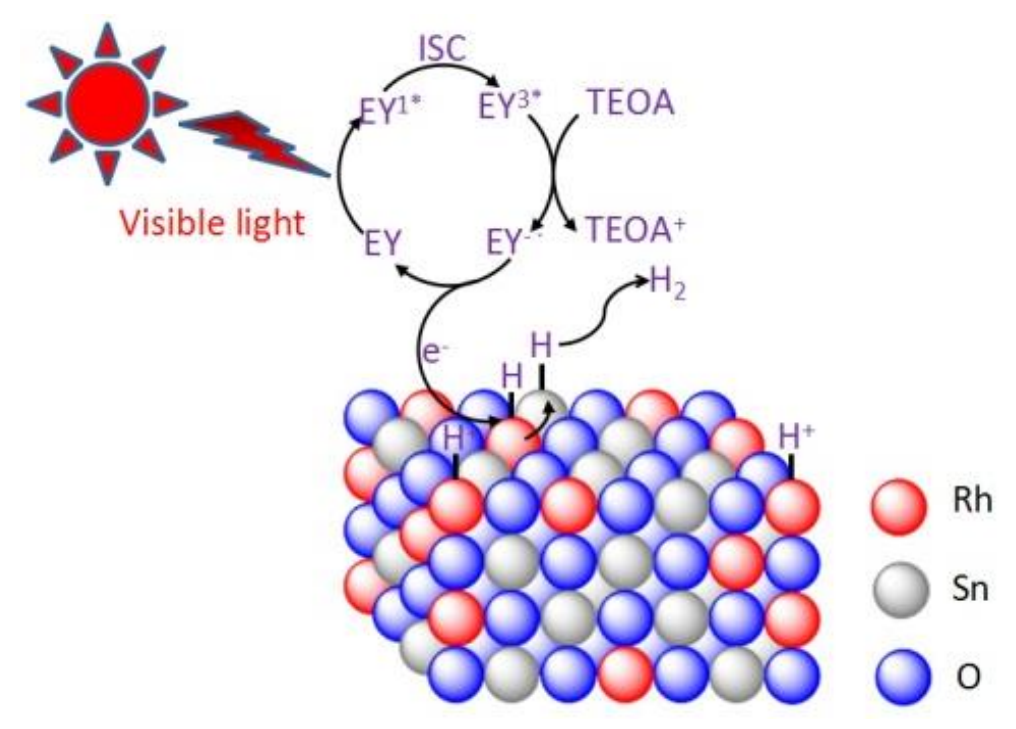

